\title{
A formação da classe empresarial brasileira
}

\author{
The formation of the brazilian business class
}

Virgilius de Albuquerque ${ }^{1}$

\begin{abstract}
Resumo
Analisamos a formação do empresariado nacional como ator político. Para tanto, foi desenvolvida uma abordagem diacrônica que narra as sucessivas etapas de formação do estado nacional vis-à-vis a consolidação da classe empresarial. A aristocracia agroexportadora possibilitou, mediante o processo de acumulação de capital, a formação gradativa da classe industrial brasileira que foi se cristalizando ao longo da República Velha. O projeto industrial adquiriu caráter hegemônico a partir da República Nova e do Estado Novo, e se consolidou ao longo das diversas mudanças de interlocução política desenvolvidas pelo estado brasileiro, incluindo, além da classe agrária, o capital internacional, a burguesia estatal, e, mais recentemente, novos estratos da sociedade civil. Consoante as mudanças na estrutura política do estado brasileiro, a classe empresarial foi buscando novas formas de mediação política. Evoluiu do patrimonialismo para modos de representação corporativa, associativa, constituiu organizações civis de estudos e pesquisas de temas transetoriais, ampliou sua influência no legislativo, e participou de um amplo processo de concertação política, sem, contudo, abandonar métodos clientelistas e vínculos pessoais. O empresário, como ator político, enfrenta uma disjuntiva entre um arranjo de representação complexo e maleável e a constituição de plataformas políticas abrangentes que representem um interesse nacional.
\end{abstract}

Palavras-chave: estado brasileiro; empresariado nacional; formação de ator político; canal de mediação; representação política.

\begin{abstract}
We analyze the formation of the national business community as political actors. We develop a diachronic approach that relates the successive stages of formation of the nation state vis-à-vis the consolidation of the business class. The agrarian export oriented aristocracy through the process of capital accumulation enabled the gradual formation of the Brazilian industrial class that was crystallized throughout the Old Republic. The industrial project has acquired a hegemonic character from the New Republic and the New State and consolidated throughout the various changes in political interlocution undertaken by the Brazilian government, including, besides the agrarian aristocracy, international capital, the state bourgeoisie and, most recently, new strata of civil society. In tune with the changes in the political structure of the Brazilian state, the business class has sought new forms of political mediation. This evolved from patrimonialism to corporative and associative modes of representation, constituting civil organizations for cross-sector themes in studies and research; it expanded its influence in the Legislature, and participated in a broad political
\end{abstract}

Artigo submetido em dezembro de 2010 e aceito para publicação em março de 2011.

1 A

do Tribunal de Contas da União; Professor do curso de Administração da EBAPE/FGV e do curso de Relações Internacionais da ESPM-Rio; Doutor em Administração pela EBAPE/FGV; Mestre em Relações Internacionais pela PUC-Rio. Endereço: Av. Pref. Dulcídio Cardoso, 800, ap. 507, CEP 22620-311, Rio de Janeiro, RJ. E-mail: virgilius.albuquerque@fgv.br 
consensus, but without abandoning patronage methods and personal ties. The entrepreneur as a political actor faces a disjunctive between a complex and flexible array of representation, on the one hand, and the establishment of comprehensive policy platforms that represent the national interest, on the other hand.

Keywords: brazilian nation-state; business class; formation of political actor; channel mediation; political representation.

\title{
Introdução
}

\begin{abstract}
"Para mim, é estrutura tudo o que resiste ao tempo da história, o que dura e até perdura - logo, algo bem real, e não a abstração da relação ou da equação matemática".
\end{abstract}

Fernand Braudel ${ }^{2}$

Objetivamos apresentar, neste trabalho, evidências empíricas, constatadas historicamente, que descrevam as estruturas de mediação política constituídas pelos empresários e pelo Estado brasileiro. Desse modo, procuramos enumerar todas as modalidades de estrutura de representação de interesse e os padrões de ação coletiva da classe empresarial que foram constituídos historicamente.

Com esse propósito, discorreremos, a partir da exposição de situações históricas nacionais de natureza econômica, sobre o comportamento de atores políticos públicos e de agentes empresariais na condução de políticas públicas. Inicialmente, será ilustrada a contenda entre os empresários agrários e industriais no processo de redefinição da matriz econômica do país, desde a República Velha até a reforma do Estado, iniciada na década de 1930. Posteriormente, face à hegemonia do projeto industrial, será abordado o papel da classe empresarial brasileira na condução da política de regulação do capital internacional. Subsequentemente, o projeto desenvolvimentista do Estado burocrático-autoritário do regime militar será apreciado. Na fase seguinte, será apresentada a política de desestatização, conduzida a partir da segunda metade da década de 1980. As formas de representação política posteriores à Constituição de 1988 serão abordadas em seguida. Será, também, tecida uma breve sinopse dos conselhos governamentais. Por fim, sintetizaremos as formas de mediação empregadas pela classe empresarial.

\section{A República Velha}

Mello (1982) afirmou que foi o complexo exportador cafeeiro nacional que criou as condições endógenas de acumulação de capital necessária para o desenvolvimento do modelo capitalista no Brasil, e para o início do nosso processo de industrialização. Desse modo, a burguesia cafeeira foi a matriz social da burguesia industrial, haja vista o fato de ser, até então, a única classe dotada de capacidade de acumulação de capital. Esse autor define o período de 1888 a 1933 como o nascimento e a consolidação do capital industrial constituído, predominantemente, pelo setor produtor de bens de consumo não-duráveis. Na década de 1930 esgotou-se o padrão de acumulação capitalista centrado no complexo cafeeiro ${ }^{3}$.

${ }^{2}$ In: Reflexões sobre a História. São Paulo: Martins Fontes, (1992, p.37).

3 Mello (1982) complementou seu trabalho afirmando que o período de 1933 a 1955, correspondeu a uma fase de transição, que denominou de processo de industrialização restringida. Isto porque, conquanto existisse um movimento endógeno de acumulação do capital industrial, a industrialização se encontrava restringida devido à insuficiência de bases técnicas e financeiras da acumulação. 
Faoro (2001), ao reconstruir a longa evolução histórica de formação do Estado brasileiro, sustentou que ele era apropriado por uma classe dirigente que incorporava o país como uma propriedade privada. Inicialmente, essa condução política ocorreu sob a forma patriarcal, subsequentemente, a modalidade observada foi o patrimonialismo. Nessas concepções estatais, os donos do poder do sistema patronal do Estado encapsularam-se, sob a forma de estamento ${ }^{4}$, em torno de seu aparato até a revolução de 1930, que marcou o seu crepúsculo, estigmatizado pela República Velha. Ilustrativamente, os membros componentes do estamento, eram civis com funções administrativas determinadas dentro do aparelho estatal, legisladores, magistrados, capitalistas comerciais, clero, e militares. Malgrado a estrutura patrimonial ter sido substituída por um modelo burocrático, esse autor observou que a sociedade civil, em seu sentido lato, permaneceu alijada do processo de condução política do Estado.

A apostasia secular entre o Estado e seu corpo dirigente, socialmente organizado sob a forma de estamento, por um lado, e a sociedade civil que não fazia parte da classe estatal, por outro, marcou profundamente uma outra característica da prática de governo e do comportamento do povo brasileiro. O insulamento do estado, corporificado mediante a sua classe estamental, das demais classes sociais gerou uma sociedade que não se politizava devido à resolução das questões públicas dentro dos gabinetes palacianos. A existência de um estado não-representativo e o enraizamento de uma cultura de alienação política desencadeou um fenômeno social em que a sociedade civil se acostumou a deixar o governo resolver os seus próprios (da sociedade civil) problemas. Por conseguinte, esse comportamento cultural de esperar tudo do governo, fomentou nossa tradição assistencialista e clientelista de sempre procurar guarida no seio do Estado.

\section{A República Nova}

A revolução de 1930, emblemada pela ascensão de Vargas, foi a primeira tentativa de romper com o status quo vigente, simbolizado pela classe estamental do estado brasileiro, que era, inicialmente, representada pela burguesia comercial de origem portuguesa e, subsequentemente, pela aristocracia rural e pelos comandantes militares. Vargas procurou legitimar seu governo com o apoio popular. Para tanto, efetuou reformas constitucionais e introduziu as grandes questões sociais na agenda do estado. Com relação ao aparato estatal, procurou desconstituir a classe estamental por intermédio da impessoalização e burocratização do aparelho administrativo do estado. A revolução paulista de 1932 reincorporou a classe rural e renovou a importância do alto segmento da classe militar, entretanto sem a preponderância de outrora (FAORO, 2001).

Após a revolução de 1932, a constituição do Estado nacional foi influenciada pelo esforço de agregar tanto os atores societais tradicionais, representados pelo segmento agrário-exportador e pela pequena burguesia supridora do mercado interno, como também os setores sociais emergentes, expressos por grupos industriais, pelas classes médias urbanas, profissionais liberais, e facções militares, principalmente. A ausência de um bloco de poder hegemônico ocasionou a crise política de 1930, e resultou na reestruturação do aparelho do Estado nas suas formas de articulação com a sociedade civil, de modo a recepcionar esses segmentos representativos na estruturação de dominação estatal (DINIZ, 1978; DINIZ e BOSCHI, 1978).

Este é o momento histórico que melhor sintetiza a revolução burguesa no Brasil. De acordo com Fernandes (1976), a associação entre as classes industriais emergentes e a oligarquia agrária e comercial exportadora assegurou a acumulação de capital em decorrência da desigualdade social brasileira. Essa aliança, combinada com a nossa condição de economia capitalista periférica e dependente, resultou em um modelo de revolução conciliadora, descredenciando a burguesia nacional de qualquer papel de agente modernizador, quiçá,

4 Segundo Faoro (2001), o conceito de estamento empregado emana de Weber, que prelecionava que as classes sociais são classificadas de acordo com (i) o grau de permeabilidade, ou seja, migrações interclasses, (ii) as sanções impostas aos membros da classe, e (iii) o seu nível de coesão e diferenciação funcional. 
revolucionário. Com relação às classes empresariais, foi constituído o modelo corporativo ${ }^{5}$ com a inclusão daquela classe no aparelho decisório do Estado, estruturado na forma de conselhos estatais.

Dessa forma, observaram Diniz e Boschi (2004), o Estado arrefecia a organização autônoma dos principais grupos empresariais, ao mesmo tempo em que induzia o processo de formação das identidades coletivas dessa classe, o que foi facilitado ante a ausência da mediação dos partidos políticos. Constituía-se, naquele momento, a identidade do empresário industrial como ator político nacional, papel aprofundado e consolidado no Estado Novo ${ }^{6}$. Diniz (1993) observa que essa configuração corporativista de participação nas instâncias organizacionais públicas de representação de interesses, que incorporou o empresariado de forma mais ativa, e, mesmo o trabalhador, de forma menos participativa, precedeu a institucionalização das regras de competição parlamentar-partidária.

Essa característica brasileira - e latino-americana - subnutriram a capacidade de penetração social, de articulação política, e de reivindicação de demandas socialmente representativas, por via dos partidos políticos. Houve a marginalização da arena parlamentar e a inviabilização da vocação dos partidos políticos de participarem da constituição de identidades coletivas e de veicularem demandas mais universalistas. Por conseguinte, tornaram-se dependentes do Executivo, que retroalimentava um Estado fragmentado e caracterizado por desigualdades estruturais em termos de classes sociais, setores econômicos, regiões geográficas, e níveis de renda.

Por sua vez, na esfera da classe trabalhadora, além das organizações corporativas operárias, foram adotadas políticas sociais para a sua conformação a um novo pacto de poder, capitaneado pelo Estado, com vistas à construção e sustentação de uma nova ordem econômica, dinamizada pela industrialização. Ao contrário das corporações empresariais, as entidades operárias não participavam dos conselhos técnicos, tendo, sua atuação, sido restringida para a área trabalhista e a previdenciária, que estavam sob a tutela do Ministério do Trabalho7. Substantivavam-se, assim, os instrumentos de cooptação exercidos pelo poder Executivo do Estado, que foram caracterizados pelos canais de mediação corporativos. Em sua gênese, a classe empresarial industrial desconhecia as formas de representação pluralista, consubstanciadas nos partidos políticos e nos processos eleitoral e parlamentar. E, desde a sua concepção, o arcabouço corporativista nacional foi de natureza setorial e bifronte, caracterizado pela ausência de representação dos trabalhadores nas instâncias decisórias das políticas de ordem econômica (DINIZ, 2000; BOSCHI et al., 2000).

\section{O Estado de Compromisso e a Opção Industrial}

A reforma político-institucional ocorrida na década de 1930 visava desarticular o Estado oligárquico-agrário representativo da República Velha - parcialmente reconduzido às instâncias do poder após a revolução

5 As organizações patronais e operárias apresentavam personalidade jurídica de entidades paraestatais. Com relação aos organismos corporativos patronais, Diniz e Boschi (2004, p. 44-45) aduziram que obedecem “... aos requisitos de uma legislação específica, seu funcionamento pauta-se pela garantia do monopólio de representação, pelo princípio da unicidade sindical e, fundamentalmente, pela obrigatoriedade da contribuição financeira, independentemente da afiliação".

6 Camargo (1992, p. 32) denominou esse arranjo, consolidado a partir de 1937, de pacto corporativo que "... pode ser representado através do polígono getuliano, constituído de vértices compostos, no eixo simbólico, pelos intelectuais e pela lgreja; e no eixo social da produção pelos empresários e pelos trabalhadores. Nos pontos extremos do eixo territorial encontramos os militares... e as elites regionais na base mediando as decisões entre os municípios e o poder central".

7

Mainwaring (2001, p. 281) ao comentar a constituição do corporativismo na gestão Vargas, observou que "... as instituições corporativistas gradualmente incorporaram os sindicatos urbanos ao sistema político sob a égide do Estado... Por meio de uma variedade de instrumentos, os códigos corporativistas fortaleceram o controle do Estado sobre os sindicatos". 
constitucionalista de 1932 - e reorganizar o Estado para incorporar as demandas políticas dos novos atores sociais que emergiram com o início do processo de industrialização. Essa reforma teve início durante o governo constitucional de 1934 a 1937 e foram aprofundadas com a ditadura do Estado Novo, instaurada naquele último ano. Naquele período, os canais de mediação dos interesses societais seriam transpostos do parlamento para as instâncias corporativas e os conselhos consultivos burocráticos. Consistiu no primeiro projeto nacional de modernização e racionalização do aparelho do Estado, sintetizado pela institucionalização de uma burocracia de corte weberiano.

O Estado varguista adquiriu amplo domínio na ordem econômica e social e foi o progenitor do estadoempresário $^{8}$ e do processo de industrialização substitutiva. A partir de 1937, até a queda de Vargas em 1945, o processo decisório foi encapsulado e a implementação das políticas de governo foi assegurada mediante o emprego de recursos coercitivos. Foi criada uma estrutura corporativa composta por institutos, autarquias, e conselhos técnicos ${ }^{9}$, sendo que esses últimos apresentavam natureza consultiva, normativa, e/ou deliberativa, nas áreas de consumo, produção, comércio exterior, e proteção da indústria nascente. Os grupos de interesses econômicos passaram a ter representação direta nos conselhos técnicos, conquanto predominasse a posição burocrática, mormente a partir de 1937, quando praticamente exauriram-se as formas de mediação política. Essa constante conjuntura de força nuclear estatal, que exercia força centrípeta sobre os demais agentes econômicos, propiciou um vácuo político, qual seja, a inexistência de um projeto hegemônico da burguesia industrial nacional, pois esse segmento estava adstrito a interesses particularistas (DINIZ, 1978; 2000).

A classe empresarial industrial procurava exercer pressão contínua contra as práticas comerciais subjacentes ao ideário de livre comércio e laissez faire, então predominante na política comercial brasileira. A importação de produtos estrangeiros inviabilizava a concorrência nacional no mercado doméstico e, dessa forma, impossibilitava o desenvolvimento de setores industriais nacionais. Por conseguinte, essa lógica reforçava a burguesia rural e o seu projeto de um país eminentemente agrário. Por outro lado, em contraponto ao predomínio da agricultura, a baixa heterogeneidade regional e setorial dos segmentos industriais nascentes, e a existência de um projeto comum de industrialização do país, possibilitaram a consubstanciação dos interesses dos agentes industriais em associações de classe, e.g., federações, e a aglutinação do empresariado em forma de bloco, ou seja, em grupos de interesse (DINIZ e BOSCHI, 1978).

A baixa taxa de dissensão entre os setores industriais, observada naquele período, não encontraria similaridade em outro momento da história do empresariado industrial brasileira, em que predominaram a formação de entidades representativas específicas e assimétricas entre si. O oponente da contenda era claro: os produtores de bens importados e os segmentos societais representativos da economia agroexportadora. Esses grupos expressavam uma ideologia condutora a um retrocesso histórico para a reintegração do país a uma divisão internacional do trabalho, desinteressante para a classe industrial emergente.

Releva-se a existência de uma etapa de transição, em que nenhuma das duas classes econômicas majoritárias detinha condições hegemônicas para o exercício do poder. Portanto, as forças preponderantes - malgrado não-hegemônicas - constituíram uma coalizão de acomodação em que o Estado assumia compromissos com todos esses grupos - oligárquicos (aristocracia agroexportadora), militares, e setores emergentes (grupos empresariais, classe média urbana) - conquanto fossem os mesmos divergentes. Destarte, o ajustamento entre as diversas relações de força antagônicas impossibilitou a ocorrência de mudanças estruturais.

A partir do Estado Novo, houve uma centralização do processo decisório - até então disperso - nos órgãos burocráticos do governo. Contudo, a proliferação de órgãos técnicos e consultivos pulverizou a prática

8 Diniz (2000, p. 35) observa que "[e]ntre 1940 e 1945, 21 empresas públicas haviam sido criadas, entre sociedades de economia mista, autarquias e fundações, sendo 10 empresas do setor produtivo".

9 Dentre eles, destacavam-se o Conselho Nacional do Café - criado em 1931 e substituído pelo Departamento Nacional do Café, em 1933, o Conselho Federal de Comércio Exterior, o Conselho Técnico de Economia e Finanças, o Conselho Nacional de Política Industrial e Comercial, o Conselho Superior de Tarifas, e a Comissão de Planejamento Econômico (DINIZ, 1978, p. 21; DINIZ, 2000, p. 35). 
governamental de cooptação e canalização dos interesses privados. Por conseguinte, as constantes dissensões interburocráticas, derivadas da dinâmica das relações de força entre os diferentes grupos de interesse, procrastinavam o processo decisório e conferiam uma grande inércia ao núcleo duro do poder. Diniz (1978) ilustrou as consequências dessa arquitetura institucional com as dissidências ocorridas entre a Comissão de Planejamento Econômico e o Conselho Nacional de Política Industrial e Comercial sobre o planejamento econômico, além das disjunções temáticas verificadas entre o Conselho Federal de Comércio Exterior CFCE, e a Coordenação da Mobilização Econômica acerca do levantamento de custos industriais, e entre o CFCE e o Ministério da Agricultura sobre a criação de órgão de fomento setorial.

No início da República Nova, não havia política industrial, instrumentos de crédito a médio e longo prazo ${ }^{10}$, nem benefícios fiscais. Igualmente, a função de regulamentação, assim como a de coordenação, e de planejamento das atividades econômicas não eram exercidas. Porém, já ao final do governo Vargas, a industrialização suplantou a vertente agrária da economia. No que tange ao capital externo, observamos que a oposição do segmento industrial era contra os exportadores internacionais que inviabilizavam a produção doméstica, em vez do capital internacional, o qual era cortejado para a expansão da atividade industrial doméstica.

Nesse particular, o empresariado nacional reconhecia a inviabilidade de se desenvolver um capitalismo industrial no país alavancado, predominantemente, pelo capital doméstico. Defendia, outrossim, uma forma de desenvolvimento associado com a participação igualitária de ambos os capitais no processo de industrialização, reservando, contudo, as inversões estrangeiras para os setores economicamente distantes do industrial brasileiro. Advogava uma campanha protecionista de controle das importações como forma de resguardar o incipiente parque industrial brasileiro. Da mesma forma, criticava os tratados de livre comércio, porquanto não protegiam os produtores locais em face dos produtos oriundos dos países industrializados. Enfim, sustentava a necessidade de subordinar a política de comércio exterior, bem como o capital internacional aos interesses da burguesia industrial doméstica (DINIZ e BOSCHI, 1978).

Com relação à intervenção estatal, a posição burguesa era mais refratária. Refutava a atuação empresarial e centralizadora do Estado, e prescrevia-lhe uma intervenção eminentemente regulatória e de controle, dentro da esfera de influência da classe industrial, cuja natureza era tipicamente regional, disciplinando, inclusive, a entrada do capital estrangeiro.

Em síntese, durante as décadas de 1930 e 1940, as preocupações da classe empresarial não eram dirigidas, eminentemente, ao intervencionismo estatal, tampouco, ao capital estrangeiro. Malgrado a coexistência e, mesmo, compartilhamento de valores com a elite agrária, o principal objetivo da burguesia industrial consistia na contenção e mitigação do predomínio da atividade agroexportadora, do setor oligárquico rural. De fato, até meados da década de 1950, a atuação da iniciativa privada nacional era pouco significativa em termos de desenvolvimento de um projeto de industrialização, bem como, de articulação sob a forma de classe societal preponderante. Devido à diversidade da capacidade produtiva, bem como, à heterogeneidade setorial e regional, que implicavam na atomização da classe empresarial, as intervenções para a defesa de seus interesses diversificados eram caracterizadas pela atuação fracionada, tanto ao nível setorial quanto local. Ademais, as intervenções eram empreendidas, de forma usual, pelo empresário individualmente (CARDOSO, 1964; DINIZ e BOSCHI, 1978; DINIZ, 1993).

\section{A Preocupação e a Aliança com o Capital Internacional}

O ideário do industrialismo nacional estava dissociado de um projeto nacional-desenvolvimentista, bem como, do intervencionismo estatal. Somente a partir da década de 1950, adveio a tese nacionalista que se

\footnotetext{
${ }^{10}$ Apenas em 1937, foi criada uma carteira institucional de crédito doméstico do Banco do Brasil destinada à aquisição de máquinas e equipamentos industriais.
} 
fundava no preceito de desenvolvimento autônomo ${ }^{11}-\mathrm{e}$, mesmo, estatizante - da indústria nacional como estratégia de independência política e econômica dos países periféricos ${ }^{12}$. Contudo, essa doutrina foi esposada por intelectuais de esquerda, técnicos e especialistas da burocracia do Estado, militares, e pelas massas populares, em vez da elite industrial propriamente dita, porquanto a heterogeneidade da classe empresarial dificultava a formação de uma ideologia, que pressupusesse unicidade de padrão de comportamento político e coesão de interesses do grupo postulante. Havia, inclusive, a impressão de um caráter instrumental no nacionalismo, então adotado pelos governos populistas como meio de controle das massas sociais.

Todavia, o empresariado nacional participou da articulação para a abertura econômica ao capital externo na segunda metade daquela década. Existia uma conjugação de interesses capitalistas internos e internacionais. Esse apoio foi motivado pela percepção de aproveitamento das externalidades dinamizadas pela empresa multinacional instalada no país na forma da oferta de bens intensivos em capital e da utilização de tecnologia avançada. Um vetor adicional correspondeu a uma estratégia de contenção do processo de expansão estatal na esfera produtiva. Inobstante, o setor industrial defendia a presença do Estado na atividade econômica (mas não empresarial) porquanto, desse modo, assegurava maiores possibilidades de prosperidade econômica ${ }^{13}$ (CARDOSO, 1964; DINIZ e BOSCHI, 1978).

No período correspondente à década de 1950, houve um novo ciclo de acumulação, expresso pelo processo de industrialização pesada, e caracterizado pela implantação de um conjunto de indústrias complementares. Naquela fase, houve um crescimento acelerado da capacidade produtiva do setor de bens de produção e do setor de bens duráveis de consumo. Aquele processo foi apoiado pelo Estado e pelo capital estrangeiro, que se internalizou sob a forma de capital produtivo. O capital industrial nacional, também, se beneficiou da aliança entre Estado e capital estrangeiro. A entrada da empresa multinacional criou mercados para a firma brasileira de pequeno e médio porte, e.g., setor metalmecânico, onde as empresas de autopeças orbitam em torno das montadoras (MELLO, 1982).

Draibe (1985) chamou a atenção para o fato de que uma nova inflexão na forma do Estado, caracterizada pelo reforço e surgimento de novos órgãos e mecanismos de intervenção estatal, indutores do desenvolvimento econômico, teve início, ainda, durante o segundo governo de Vargas. Destacamos a fundação da PETROBRAS e a criação do Banco Nacional de Desenvolvimento Econômico - BNDE, em 1953. O programa intitulado Plano SALTE (apoiados nos eixos de saúde, alimentação, transporte, e energia) do ex-presidente Dutra - em menor grau - e o Plano de Metas do governo Kubitschek foram continuidades de um movimento deliberado de transformação conduzido por Vargas.

Não obstante, cabe ressaltar a inovação subjacente à implementação do Plano de Metas, que, definitivamente, pôs termo ao ciclo de industrialização restringida configurado por Mello (1982). Uma parcela da burocracia do Estado foi organizada sob a forma de grupos executivos e de trabalhos para planejar e implementar um novo projeto de desenvolvimento industrial, alicerçado no Estado ${ }^{14}$ - por meio da empresa

${ }^{11}$ De acordo com Camargo (1992, p. 27), o projeto nacional-desenvolvimentista decorreu de uma tradição histórica de autonomia soberana do Executivo. Essa tendência foi “... sacramentada pelos intelectuais orgânicos que primeiro formularam [tal projeto] ....Para todos eles o problema era praticamente o mesmo. Nada mais urgente do que racionalizar e fortalecer o aparelho do Estado, 'proteção simbólica da unidade da Nação"'. De fato, o empresariado nacional atuou de forma tangente a esse projeto, uma vez que articulou a entrada do capital estrangeiro e procurou restringir o escopo empresarial do Estado.

12

Diniz e Boschi (1978, p. 102) conceituaram nacionalismo como “... uma participação contrária a esta participação [(do capital estrangeiro)] ou mesmo a formulação e defesa de medidas visando à garantia de prioridade para o capital nacional no processo de implantação e consolidação do capital industrial ...".

13

Cardoso (1964, p. 135) reproduziu pensamentos industriais de que o "Estado deve secundar a iniciativa privada, criando condições para que a indústria possa desenvolver-se plenamente no regime de liberdade" e que as "inversões estatais são necessárias nos setores em que a baixa rentabilidade ou o excesso de riscos desestimulem a iniciativa particular".

${ }^{14}$ Bianchi (2001, p. 125) afirmou que apesar do funcionamento de uma estrutura partidária, “... a relação do empresariado com o Estado continuou a ser levada a cabo através do Executivo ... Esse parece ter sido o caso dos 'grupos executivos' criados pelo governo Juscelino Kubitschek com representantes do setor privado e estatal ....". 
estatal - na empresa privada nacional, e no capital da empresa multinacional. Aquela elite burocrática representou uma nova modalidade de interação com os segmentos organizados da sociedade civil. Em uma análise pregressa, os grupos executivos são caudatários dos quadros técnicos do Departamento Administrativo do Serviço Público - DASP. Posteriormente, essa modalidade de articulação política com vistas à definição conjunta das diretrizes pública e privada, seria transfigurada sob a forma de anéis burocráticos, metáfora criada por Cardoso (1977).

\section{Nacionalismo e Estado Burocrático-Autoritário}

Diniz e Boschi (1978) prelecionaram que a assunção do Estado autoritário em países capitalistas periféricos decorreu de crises econômicas decorrentes do esgotamento do modelo de industrialização por substituição de importações, e da incapacidade da classe burguesa de implementar um projeto de hegemonia perante a sociedade civil. Nessa perspectiva, há uma tendência em relevar o papel protagonista desempenhado pelo Estado em detrimento à importância dos diversos grupos sociais. Uma interpretação política menos dicotômica - Estado forte e sociedade fraca - em que a participação dos grupos societais é mais ressaltada, está apresentada na literatura relativa aos estudos do estado burocrático-autoritário. Essas duas abordagens Estado protagonista, por um lado, e Estado e grupos societais como atores principais, por outro - podem ser encontradas na literatura política, social e econômica do Brasil. Se a abordagem do Estado autocrático preponderou na gestão Vargas das décadas de 1930 e 1940 (e até 1950), a perspectiva burocrático-autoritária foi majoritária nos estudos dos governos militares. Uma hipótese plausível é o maior desenvolvimento industrial existente no segundo período, que esteve associado a uma burguesia industrial e urbana mais robusta e à constituição de uma burocracia governamental insulada e de maior envergadura técnica.

Durante o regime militar de 1964 a 1985, as principais características do modelo varguista foram aprofundadas, tais como as prerrogativas legislativas do Executivo, o arrefecimento assimétrico do Legislativo, o padrão de atuação corporativo bifronte e fragmentado setorialmente, e o insulamento tecnoburocrático. Houve um aumento da burocracia, refletida na expansão de conselhos técnicos com participação empresarial ${ }^{15}$, assim como, do conjunto de autarquias, fundações e empresas públicas e de economia mista ${ }^{16}$. (DINIZ, 2000).

No início do regime burocrático-autoritário, a atuação do Estado como agente catalisador de recursos e investimentos, acumulador de capital, mediador doméstico, e interlocutor junto à sociedade capitalista internacional arrefeceu definitivamente o projeto nacionalista. A necessidade do capital internacional para patrocinar o projeto desenvolvimentista - não mais nacionalista - engendrou o modelo tripartite de desenvolvimento nacional. Esse modelo estava assentado na participação conjunta do Estado, da empresa multinacional, e do setor industrial brasileiro. O manancial de crédito do empresariado nacional residia nas agências do Estado, constituindo um liame entre Estado e burguesia. Apesar da relação de assimetria em favor do Estado, esse dependia do apoio político dos grupos econômicos domésticos para legitimar sua autoridade.

Com relação à estrutura de representação de interesses, as associações extracorporativas expandiram-se no período militar. A intensificação do processo de industrialização acentuou a diversificação da produção, bem como a diferenciação das firmas em termos de escala e escopo. Essa alternativa orgânica apresentava mais agilidade na defesa e promoção dos interesses de segmentos empresariais, ao mesmo tempo em que não estava limitada em bases regionais. De forma geral, as associações foram criadas para atuar como lobistas; nesse sentido, elas eram constituídas pelas firmas de maior porte e apresentavam um número reduzido de

\footnotetext{
${ }^{15}$ Foram, então, criados, entre outros, o Conselho Monetário Nacional - CMN, o Conselho de Desenvolvimento Industrial - CDI, o Conselho de Desenvolvimento Econômico- CDE, e o Conselho Interministerial de Preços - CIP.

${ }^{16}$ Nesse período, foram criadas 68 agências e 267 empresas estatais.
} 
afiliados. Houve, portanto, uma manutenção da tendência de pulverização e especialização de representatividade o que, a fortiori, dificultou - ou mesmo inviabilizou ab initio - a concepção de políticas cooperativas e coordenadas de ação política coletiva da classe empresarial.

A prática de negociações compartimentalizadas entre as instâncias privada e pública oriunda desse arranjo estrutural fragmentado, resultou na multiplicidade de interlocutores burgueses junto às interfaces estatais. Esse arranjo estrutural deu a conotação de que o empresariado é, tradicionalmente, um ator político fraco ${ }^{17}$, em que o alcance das negociações políticas fica circunscrito ao seu setor. Ou, de forma mais atenuada, de um grupo social que ocupa uma posição de subordinação face ao Estado.

Em contraponto, algumas características dessas modalidades de arranjo enfraquecem qualquer postulado de burguesia fraca ${ }^{18}$. Elas podem ser deduzidas pela capacidade do empresariado de formalizar alianças com o capital multinacional e com o Estado, e pela plasticidade articulatória dos segmentos empresariais, expandindo as possibilidades de efetuar participações políticas simultâneas nas esferas do Estado e de suas agências governamentais.

Três características sobrelevaram-se no período militar. Inicialmente, a acentuação da competição intersetorial que resultou no fortalecimento daqueles segmentos mais intensivos em capital e tecnologia, em que predominavam o capital estatal e o estrangeiro, tais como, as indústrias de bens de capital e de bens de consumo duráveis, em contraste com as indústrias nacionais tradicionais dos ramos de alimentação, têxtil e bens de consumo não-duráveis. Na década de 1980, o Brasil alcançou um alto grau de integração intersetorial e de diversificação da produção. A estrutura industrial brasileira, onde o complexo químico e o metalmecânico representavam cerca de $60 \%$ da produção industrial naquela época, não era significativamente distinta daquelas observadas nas economias da OECD (COUTINHO e FERRAZ, 2002). Inobstante o domínio exercido pelos capitais público e internacional, o capital doméstico apresentava uma peculiaridade que lhe auferia capacidade de barganha, qual seja, sua participação em todos os ramos da atividade industrial (Diniz e Boschi, 1978).

Segundo, a maior fragmentação da estrutura do aparelho estatal que incrementa as modalidades de acesso ao governo. Não obstante, a concentração do processo decisório nos núcleos de poder estatal - principalmente, aqueles de maior envergadura econômica nacional - a crescente diferenciação e especialização das agências estatais observadas naquele período, induziram novas esferas de influência e formas de relacionamento empresarial com as instâncias do Estado. As distintas formas de absorção dos interesses societais ampliaram o espectro de alternativas e propiciaram a gestação dos processos decisórios de modo mais consonante com as demandas sociais. Por outro lado, essa multiplicidade orgânica criou 'áreas cinzentas', constituindo, por conseguinte, competências burocráticas fragmentadas, conflituosas e concorrentes, haja vista a superposição de jurisdições, e a sobreposição de instâncias governamentais interlocutórias e decisórias ${ }^{19}$ (DINIZ, 1993). Essa formatação, além de procrastinar o processo decisório, dificultava a adoção de ações políticas coordenadas.

17 Mancuso e Oliveira (2006) rejeitaram a postulação de debilidade de articulação política do empresariado nacional. Afirmam que a capacidade de ação coletiva do empresariado pode ser evidenciada pelos movimentos de redução do custo-Brasil, no plano interno, e pela formação da Coalizão Empresarial Brasileira - CEB, em 1996, para aglutinar os interesses empresarias multisetoriais nas negociações da ALCA. Esses autores informaram que a CEB é composta por 6 confederações, 28 federações, 6 sindicatos empresariais, 48 associações empresariais, e 10 empresas.

${ }^{18}$ Diniz e Boschi (1978, p. 168) consignaram que “... ao nível da elite industrial, existe um alto grau de sedimentação e consolidação. Em outras palavras, esta elite, longe de caracterizar-se por um padrão de rotatividade, apresenta um grau de permanência bastante acentuada ao longo do tempo" relaxando, destarte, a tese de fragilidade política da burguesia lato sensu. Diniz (1978, p. 28) atentou para a leitura enviesada de que as "... estruturas de representação de interesses do setor empresarial sejam interpretadas como reflexo da fraqueza ... quando podem significar esforços adaptativos a uma certa forma de organização do Estado".

19 Ilustrando, Diniz e Boschi (1978, p. 165-6) relataram que no setor de bens de capital havia cerca de 22 órgãos governamentais conexos. 
Terceiro, ao contrário do regime revolucionário varguista, o empresariado não tinha assento de representação nos conselhos econômicos, cujo principal era o Conselho de Desenvolvimento Econômico - CDE, modelo de centralização burocrática caudatário dos Grupos Executivos do governo Kubitschek. A grande novação de representação verificada nesse período foi a constituição amorfa dos anéis burocráticos ${ }^{20}$, expressão cunhada por Cardoso (1977). Reflete os contatos pessoais mantidos por empresários com autoridades públicas de diferentes esferas governamentais com vistas ao atendimento de suas demandas. Essa modalidade informal de exercício de pressão substituiu a perda de representatividade das corporações industriais nos conselhos e demais fóruns de decisão do Executivo, e as práticas clientelistas que eram exercidas, também, no âmbito do parlamento, então, esvaziado em suas prerrogativas políticas. Essa mesma práxis política ajuda a compreender porque o movimento antiestatizante verificado no início do governo Geisel apresentou a classe empresarial fragmentada, tanto em nível regional, como em termos de atividade econômica - industrial, agropecuária, financeira, e comercial.

Em particular, com relação ao segmento industrial, essa classe não se apresentava organicamente articulada em termos de estrutura de representação. Por um lado, parte das entidades corporativas (confederação e federações) se posicionara contra a tendência estatizante da economia. De fato, a representatividade das entidades de cúpula era contestável, uma vez que a vigência de um regime autoritário, que regulava todos os setores da atividade econômica, esvaziava o conteúdo dos interesses mais agregados ${ }^{21}$ (Cruz, 1984). Por outro lado, os sindicatos e as associações setoriais paralelas, entes responsáveis pela resolução de questões tópicas e pela condução de interesses específicos de seus respectivos setores, permaneciam silentes. Predominava, naquele período, as decisões ad hoc, de baixa institucionalidade e destituídas de discussão com os grupos de interesse. Subjacente a esse relacionamento pessoal, havia uma relação de interdependência entre o empresário e o governo, que necessitava de seu suporte político para a manutenção de sua legitimidade, que sedimentava essa modalidade de representação de interesses.

\section{A Nova República e o Processo de Desestatização}

A condução de uma política pública pode apresentar diferentes motivações durante a sua implementação. O processo de desestatização brasileiro, ocorrido a partir da segunda metade da década de 1980, exemplifica essa possibilidade. A implantação daquela política foi a principal mudança institucional no cenário políticoeconômico após o término do regime militar.

Durante o governo Sarney, a redução do tamanho do Estado era a própria teleologia, porquanto representou um processo de redefinição da esfera de atuação do poder estatal destituído de pressões de grupos de interesse $^{22}$. Apesar da emergência das doutrinas neoliberais, o fracionamento dos grupos empresariais, cuja classe não apresentava um projeto consistente de longo prazo, por um lado, e as pressões militares e partidárias, por outro, fizeram com que a função desenvolvimentista do Estado continuasse indeterminada.

20 Diniz e Boschi (1978, p. 170) relacionaram quatro modalidades de acesso do setor industrial nacional ao Estado, durante o regime autoritário pós-64: estruturas corporativas oficiais, associações extracorporativas, anéis burocráticos, e contatos pessoais.

${ }^{21}$ A resolução de questões salariais e trabalhistas, a partilha do capital entre os diferentes setores, a estipulação dos preços, os gastos com infraestrutura, tudo isso em um ambiente de forte expansão econômica, retraiu a atividade das federações industriais. Apenas com o recrudescimento da crise econômica, e com o ressurgimento do movimento operário e sindical, a partir da segunda metade da década de 1970, as federações foram revitalizadas (CRUZ, 1984).

22

Durante o governo Sarney, foi criado, em 1985, o Conselho Interministerial de Privatização, convertido, em 1988, no Conselho Federal de Desestatização - CND, cuja coordenação coube ao BNDES. Foram privatizadas 17 empresas estatais, no total de USD 549 milhões. 
Os conflitos empresariais internos e a tradição desenvolvimentista nacional favoreceram o confinamento de uma elite ${ }^{23}$ burocrática, capitaneada pela agência governamental Banco Nacional de Desenvolvimento Econômico e Social - BNDES, na condução da política pública de desestatização (VELASCO Jr., 1997).

Por sua vez, de acordo com Velasco Jr. (1997), o governo Collor elaborou uma agenda pública que propunha uma nova formatação do Estado com o redesenho de sua capacidade de intervenção nos domínios econômicos do país24. Mesmo assim, não havia, naquele período, um consenso entre os principais atores políticos sobre os benefícios das reformas orientadas para o mercado, que, em termos concretos, correspondiam à redistribuição de recursos econômicos e à nova divisão de poder que consolidou, a partir da Constituição de 1988, a recondução de um ator político relevante, qual seja, o Poder Legislativo. Com o desmantelamento da estrutura corporativa do Estado - que ao lado das associações não-oficiais representava a forma organizacional utilizada preferencialmente pela classe empresarial - houve uma migração dos agentes econômicos para outras modalidades de acesso ao processo decisório governamental, em especial, para o espaço institucional político do parlamento. A revalorização desse fórum de representação levou, inclusive, à eleição de diversos representantes dos segmentos empresariais ao posto de parlamentares (Boschi et al., 2000; DINIZ e BOSCHI, 2004).

A desestatização dos serviços públicos apresentava baixa razão consensual. Igualmente, as coalizões de apoio e sustentação à privatização de grandes siderúrgicas - e.g., CSN e Usiminas - e dos setores petroquímico e de fertilizantes eram frágeis. Recaía-se, assim, na inequação imanente ao problema de ação coletiva, onde os interesses dos (poucos) grupos beneficiários da lógica distributiva são concentrados e significativos, ao passo que os interesses da (ampla) camada social são difusos e não-significativos. Por conseguinte, a capacidade de mobilização do primeiro estrato societal tende a ser mais articulada.

Essa política, malgrado a discordância do ex-presidente Itamar Franco com os ideais liberalizantes e reformistas, não foi descontinuada em seu governo25. Paradoxalmente, empresas associadas a fortes corporações estatais dos setores siderúrgico, petroquímico, e fertilizantes foram privatizadas em seu governo. Iniciada no governo anterior, o grupo de consolidação do programa de desestatização prevaleceu ante as forças antagônicas durante a gestão Itamar. A crise fiscal do Estado e a fragilidade de comando e direção do Estado para a reconfiguração de alianças e consequente implementação de novas políticas, contribuíram para a manutenção de um modelo de privatização não-dirigida. Esse modelo foi caracterizado pela atuação nãoseletiva do Estado na composição societária e na formulação de estratégias de acomodação de interesses. Ele foi marcado pela função minimalista governamental de fornecer e assegurar regras claras para o processo de desfazimento do ativo estatal.

Velasco Jr. (1997) concluiu que o processo de desestatização, empreendido no período de 1985 a 1994, expressou, apenas, uma estratégia de redução do tamanho do aparato estatal, mediante a privatização das funções empresariais exercidas pelo Estado. As preocupações de natureza fiscal, concernentes à diminuição do endividamento estatal, a ideologia neoliberal centrada na configuração de um estado mínimo, e a nãoconfluência de interesses em formas articuladas de grupos de coalizão, possibilitaram um enclausuramento burocrático na condução da política pública de desconstrução da intervenção estatal na atividade empresarial. Essa redução contribuiu, inclusive, para a recuperação da capacidade de intervenção do Estado uma vez que diminuiu a prática de rent seeking - acumulação de renda por atores societais a partir do controle de entidades governamentais e, por conseguinte, de seus recursos públicos - pelos agentes econômicos.

\footnotetext{
${ }^{23}$ Pertinente a enumeração de Velasco Jr. (1997, p. 19) dos componentes da elite brasileira: congressistas, administradores públicos, empresários, associações de funcionários e sindicalistas. Identificação semelhante é feita por Boschi et al. (2000).

24 Na gestão Collor foi instituído, por intermédio de medida provisória, o PND - Programa Nacional de Desestatização - e foram empreendidos 16 processos de privatização, totalizando USD 3,9 bilhões.

${ }^{25}$ Em seu governo, foram conduzidas 17 desestatizações, equivalentes a USD 4,7 bilhões.
} 
Na gestão subsequente, do ex-presidente Fernando Henrique Cardoso houve, de forma diversa, uma redefinição do papel do Estado quando, então, juntamente com as últimas privatizações de empresas produtivas, notadamente da Cia. Vale do Rio Doce, foram privatizadas concessões de serviços públicos. Naquele momento, a reconfiguração da função regulatória do Estado e a ênfase ao processo de estabilização macroeconômica passaram a integrar a agenda pública de um governo que detinha recursos de governança ${ }^{26}$ para definir os temas do debate político. As desestatizações deixaram de ser enxergadas de forma míope, visão que enfocava a redução do Estado como o principal objetivo, e que era iluminada tanto por postulados neoliberais quanto pelo arrefecimento da prática de rent seeking. O governo visava estabelecer um novo modelo de intervenção estatal nos mercados mediante a restauração de sua capacidade de investimento público, notadamente nos setores de energia elétrica, transporte e telecomunicações, e, objetivava, também, elaborar uma nova arquitetura do papel regulatório do Estado ${ }^{27}$.

\section{Representação Política na Década de 1990}

A partir da década de 1990, as estruturas de representação de interesses e os padrões de atuação política do empresariado nacional, em particular, da classe empresarial industrial, sofreram modificações em decorrência da desconstrução do Estado desenvolvimentista e da desarticulação da concepção corporativista bifronte - Estado e classe empresarial - denominada 'era Vargas', que dominara, até então, o processo de governança do país. Apresentamos as modificações da estrutura de representação coletiva de interesses do empresariado industrial, a partir da transição do modelo de regulação econômica de corte corporativista, presidido pelo Estado, para o modelo de desenvolvimento baseado na competição de interesses induzidos e mediados pelo mercado, de um lado, e pelas agências regulatórias, de outro (DINIZ e BOSCHI, 2004).

Boschi et al. (2000) salientaram que a crescente complexidade da estrutura societal brasileira, que resultou no aumento do grau de autonomia de segmentos sociais, e o processo de adensamento organizacional do Estado, desencadeados a partir do aprofundamento da industrialização na década de 1970, resultaram em um sistema híbrido de representação de interesses. A difusão de canais alternativos de manifestação de interesses é caracterizada pela conjugação de arranjos corporativistas, lobistas, clientelistas, personalistas, bem como, pluralistas (legislativo e judiciário).

A partir do governo Collor, houve uma desarticulação dos canais institucionais de mediação dos interesses empresariais junto ao Estado ${ }^{28}$, orientação essa intensificada no governo Fernando Henrique Cardoso, que enfatizava, também, a estabilidade macroeconômica. A propósito, durante o período Collor, em 1991, foram instituídas câmaras setoriais ${ }^{29}$, cuja lógica de negociação tripartite, envolvendo o Estado, o empresariado e os sindicatos trabalhistas, representava uma evolução em face do tradicional modelo bifronte que alijava a

${ }^{26}$ De acordo com Eli Diniz (apud Velasco Jr., 1997, p. 51-2), o conceito de governança abrange três dimensões. "A primeira é a capacidade de comando e direção do Estado ... Trata-se da capacidade de definir as estratégias gerais de ação e de assumir a direção efetiva do processo de políticas públicas, definindo e ordenando as prioridades. A segunda é a capacidade de coordenação do Estado entre as diferentes políticas e os interesses em jogo, de forma a garantir a coerência e a consistência das políticas governamentais .... A terceira se refere à capacidade de implementação e sustentação dessas políticas". Há um outro elemento imprescindível para a plena atuação da governança. Os processos decisórios de formulação, coordenação societal, e implementação das políticas não concluem um ciclo de governança. Para o seu êxito, é necessário acrescentar a instituição de mecanismos efetivos de controle, supervisão e cobrança societal, sintetizados no termo accountability.

27

Velasco Jr. (1997a, p. 11) aduziu que “... os mercados não necessariamente surgem com a competição, precisando ser criados por intermédio de políticas". A opção estatal de desenvolvimento econômico e social pela via regulatória, ao invés da empresarial, constava do Plano Diretor da Reforma do Aparelho do Estado, aprovado no final de 1995.

28

Naquele período foram extintos diversos conselhos e comissões em que os empresários detinham assento consultivo ou deliberativo, tais como o Conselho de Desenvolvimento Industrial - CDI, o Conselho Nacional de Comércio Exterior - CONCEX, bem como, a conversão da Comissão de Política Aduaneira - CPA em um órgão meramente técnico (BOSCHI et al., 2000).

${ }^{29}$ A câmara do setor automotivo foi a que apresentou os melhores resultados. As câmaras setoriais foram desativadas no governo Itamar Franco, em 1994. 
classe trabalhadora do processo de formulação de políticas econômicas. Conquanto setorial, essas arenas de discussão representavam um protótipo institucional do arranjo neocorporativo, compreendido como negociações tripartites que, teoricamente, se estendem de forma concertada por toda a sociedade ${ }^{30}$. Por outro lado, naquele governo, foram extintos diversos conselhos e comissões, eliminando os espaços formais de representação corporativa. Por conseguinte, intensificaram-se os vínculos personalistas e as práticas clientelistas, ao mesmo tempo em que recrudesceram as representações de interesse na arena congressual.

O alargamento desse hiato entre as esferas decisórias e o jogo de interesses resultou no incremento da atuação do segmento privado em um espectro mais diversificado de arenas; inicialmente, o espaço congressual e, mais recentemente, o judiciário. Paralelamente, a reconfiguração do processo produtivo nacional, com a entrada de empresas estrangeiras, o programa de desestatização, e as injunções externas que ocasionaram a transnacionalização econômica, resultaram na recomposição de empresas e setores tradicionais, no fortalecimento de outros segmentos industriais e, simultaneamente, no deslocamento de lideranças empresariais históricas. Contudo, cabe salientar que, malgrado a relevância do parlamento como locus de formulação e negociação de políticas públicas, a manutenção de prerrogativas legislativas do Executivo, cuja espécie normativa emblemática era a medida provisória, reforçava sua tradição de principal arena condutora dos interesses societais e instância formuladora de políticas públicas (Boschi et al., 2000; DINIZ, 2000).

A partir da redemocratização de 1985, o Legislativo foi reincorporado efetivamente à arena de interação entre o público e o privado, muito embora, desde o Congresso constituinte eleito em 1946, tenha havido representação empresarial no Parlamento. Ademais, ao longo da Nova República, particularmente, após a Assembleia Constituinte, eleita em 1986, houve um declínio numérico da representação dos grupos dos grandes setores industriais no Congresso, ao passo que foi observado um aumento na representatividade de setores empresariais emergentes, incluindo representantes de micro e pequenas empresas de serviços, localizadas em áreas urbanas.

A CNI constituiu o Conselho de Assuntos Legislativos - COAL, com o propósito de acompanhar os trabalhos legislativos de interesse do empresariado industrial, interagindo, inclusive, com os parlamentares mediante o encaminhamento de dados e propostas normativas. Essa nova conformação da estrutura de representação política dos interesses da classe empresarial foi acompanhada do incremento da atuação de entidades empresariais como grupos de pressão, e da prática de lobbying, exercido por empresas que utilizam pessoal próprio ou subcontratam serviços de consultoria e assessoria para apresentar uma rationale técnica harmônica com os interesses contratados ${ }^{31}$ (BOSCHI et al., 2000. DINIZ e BOSCHI, 2004).

Observamos que a interseção dos lobbies e grupos de interesse não se adstringe ao processo parlamentar. Elas são empreendidas, também, nas esferas burocráticas que possuem o poder discriminatório de definição de políticas públicas. E, dessa forma, quanto mais enclausurada a tecnoburocracia estatal, maior é a capacidade de alavancagem de benefícios assimétricos pretendidos pelos grupos de pressão interpessoal, caso os mesmos consigam penetrar na fronteira de insulamento estatal.

30 Reproduzimos o comentário de um ex-conselheiro do CODEFAT, sobre a consolidação de interesses corporativos que se sobrepõem ao interesse público. "É aquilo que... é chamado triângulo de ferro... um tipo de situação em que todas as partes envolvidas no desenho da política... criam uma rede de cumplicidade de interesses cujos acordos recíprocos permitem manter a política dentro daquele formato, e muitas vezes essa política deixa de servir ao que seria um interesse público mais amplo, passando a estar ajustada aos interesses que ali se consolidaram... - como se fosse uma apropriação da política pública pelos grupos envolvidos..." (THEODORO, 2002, p. 23).

“... lobbismo, no Brasil, adquire um caráter difuso, exercendo-se através dos mais variados tipos de organização, envolvendo grande número de profissionais especializados e mobilizando recursos vultosos". Há inclusive o 'lobbismo de chapa branca' conduzido por segmentos burocráticos do Executivo (BOSCHI et al. 2000, p. 66). Durante o processo constituinte, a classe empresarial criou a União Brasileira de Empresários - UBE, organização de cúpula destinada a influenciar a confecção da Carta Magna. Mais tarde, em 1991, para acompanhar projetos de interesse e influenciar a revisão constitucional de 1993-94, a elite empresarial formou a Ação Empresarial com propósito idêntico (DINIZ, 2000; DINIZ e BOSCHI, 2004; GROS, 1993). 
Evidentemente, as práticas lobistas exercidas nos círculos do Executivo são menos transparentes e permeáveis à interlocução dos diversos grupos de interesse, do que aquelas exercidas no Legislativo. Essa conjuntura isolacionista, aliada à ausência de mecanismos de accountability, é um terreno fértil para a introdução de sistema de intercâmbio sem mediação institucional, tais como as práticas clientelistas, de patronagem, e de favorecimento pessoal, que fomentam a politização em vez da assepsia política da elite burocrática. A pluralidade e fragmentação ${ }^{32}$ da representação dos interesses empresariais, que inclui a atividade lobista igualmente atomizada, caracteriza o padrão de relacionamento político da classe empresarial a partir da década de 1990.

Consentâneo com esse raciocínio é o argumento de que o encapsulamento burocrático pressupõe um jogo de soma zero, em que prevalecem relações de exploração econômica e dominação política, em vez da concertação de interesses do Estado com aqueles localizados no mercado e na sociedade. Todavia, há uma via mais producente, constituída pelo processo negocial, envolvendo os diferentes grupos de interesse que pode conduzir a um jogo de soma positiva mediante a administração de alianças e coalizões, empreendidas pelo Estado com vistas à consecução de objetivos coletivos. Um outro fenômeno, mais recente, observado nos processos decisórios governamentais, é a disjunção entre o resultado do processo eleitoral (responsiveness), de natureza pluralista, e os resultados das políticas públicas formuladas e implementadas pelo Estado (accountability). A crescente interdependência mundial, evidenciada tanto pela abertura comercial como pela liberação dos movimentos transnacionais de capital, diminui os graus de liberdade de condução das políticas econômicas domésticas. Por conseguinte, o público de representação política eleitores - difere do público a quem o governo deve, efetivamente, prestar contas - grupos de interesse nacionais e transnacionais que influenciam a condução das políticas públicas (DINIZ, 2000).

\section{Conselhos de Governo}

Historicamente, no Brasil, o Estado e a sociedade civil nunca acordaram um pacto social para a implementação de políticas reformistas e estabilizadoras. Isto porque os dois principais grupos societais, representados pelos empresários e trabalhadores, jamais foram estruturados de forma a viabilizar a implantação de políticas abrangentes. Ambos não detêm um projeto de longa envergadura, que abarque os interesses da classe como um todo, e são compostos de forma descentralizada, que dificulta a concentração e unidade de comando. Além disso, a tradição tecnocrática do processo decisório do Estado brasileiro, cujas decisões são, muitas vezes, descontextualizadas do jogo político, dos interesses empresariais e, mormente, das representações dos trabalhadores, constitui uma outra vertente inibidora da construção de concertos nacionais (DINIZ, 2000; VELASCO Jr., 1997).

A interlocução da classe trabalhadora com a burocracia estatal era, tradicionalmente, mediada pela sua organização em forma de sindicatos, cuja existência, assim como das confederações de trabalho, ilustradas pela Confederação Geral dos Trabalhadores - CGT, e Confederação Nacional dos Trabalhadores na Agricultura - CONTAG, eram normatizadas e tutoradas pelo Estado. Esse sindicalismo de Estado perdeu representatividade a partir da consolidação das centrais sindicais na década de 1980, dentre as quais, destacamos a Central Única dos Trabalhadores - CUT, a Central Geral dos Trabalhadores - CGT, a Força Sindical, e a Social Democracia Sindical. A contrapartida de representação empresarial tutelada pelo Estado eram as confederações patronais, representadas pela Confederação Nacional da Indústria - CNI, Confederação Nacional do Comércio - CNC, Confederação Nacional da Agricultura - CNA, Confederação Nacional do Transporte - CNT, e Confederação Nacional das Instituições Financeiras - CNF.

32 Diniz e Boschi (2004, p. 45) explicaram que o caráter fragmentário do corporativismo nacional decorre da dispersão territorial das representações locais, bem como da “... proibição da formação de entidades de quarto grau - como as Câmaras Empresariais, que na modalidade europeia, englobam empresários dos setores industrial, agrícola, comercial e financeiro, organizados em todo o território nacional..." 
Contudo, ressaltamos a existência de entidades de natureza bipartite, que envolvem, apenas, o empresariado e o governo. Como exemplo, mencionamos a rede nacional de entidades paraestatais representadas pelo denominado Sistema "S", composto, inter alia, pelo Serviço Nacional de Aprendizagem Industrial SENAT, Serviço Nacional de Aprendizagem Comercial - SENAC, Serviço Nacional de Aprendizagem Rural - SENAR, Serviço Social do Comércio - SESC, e Serviço Social da Indústria - SESI.

A partir da redemocratização do país e da promulgação da Constituição de 1988, houve uma revitalização dos conselhos como mecanismo de representação e participação social da sociedade civil na elaboração e gestão de políticas públicas, reintroduzindo, dessa forma, a dinâmica de um processo decisório compartilhado. Os conselhos federais de políticas sociais, como, por exemplo, o Conselho Deliberativo do Fundo de Amparo ao Trabalhador - CODEFAT, e o Conselho Nacional do Trabalho - CNTb, ligados ao Ministério do Trabalho e Emprego, representaram uma forma de participação social na discussão e gestão de políticas públicas de emprego, trabalho e renda. Analogamente, há o Conselho Nacional de Saúde - CNS, associado ao Ministério da Saúde, o Conselho Nacional de Assistência Social - CNAS, e o Conselho Nacional de Previdência Social - CNPS - ambos relacionados ao Ministério da Previdência e Assistência Social. Com relação a sua concepção e função, os conselhos apresentam diversas conformações, podendo ser parcialmente fortalecidos ou desativados por normativos do Executivo que regulamentam as suas atividades.

Os conselhos com maior representatividade de participação da sociedade civil e com maior grau de autonomia da burocracia governamental, no que se refere à concepção e gestão de políticas públicas, são constituídos de forma que as suas deliberações sejam alicerçadas nos princípios do tripartismo representantes do Estado, da classe empresarial, e de associações de trabalhadores - e do processo decisório paritário entre as diversas fontes de representação. Esse aparato institucional faz com que os conselhos possam assumir importante papel nos mecanismos de mediação política junto às estruturas do Estado, atuando, muitas vezes, como uma espécie de instância autárquica de caráter decisório (THEODORO, 2002).

As primeiras arquiteturas de tripartismo paritário ocorreram no início da década de 1990, com a instituição das Câmaras Setoriais como arenas de discussão de políticas governamentais. Entretanto, as Câmaras funcionavam como fóruns, ou seja, eram de natureza episódica, em vez de apresentarem uma constituição estrutural de caráter permanente.

Em 2003, foi criado o Conselho de Desenvolvimento Econômico e Social da Presidência da República CDES - com o objetivo institucional de articular os interesses de segmentos representativos da sociedade civil conjuntamente com os interesses do Estado. Pela primeira vez na história nacional, a classe trabalhadora foi incluída em uma modalidade de discussão suprassetorial. A constituição de um fórum negocial multilateral corresponde a um projeto nacional de concertação ${ }^{33}$, ou seja, à promoção de um processo de Concertação Nacional, conforme mencionado no sítio eletrônico da Presidência da República (CDES, 2005).

Consoante a previsão legal, as principais atribuições do CDES correspondem à assessoria para a formulação de políticas e diretrizes específicas, e à apreciação de propostas de políticas públicas e de reformas estruturais, eventualmente, submetidas pelo Presidente. Portanto, no escopo deste trabalho, as atividades desempenhadas pelo CDES podem apresentar reflexo na atuação dos diferentes grupos de interesse.

${ }^{33}$ O significado desse termo pode ser compreendido a partir do seguinte excerto constante da $1^{\text {a }}$ Carta de Concertação: "O processo de concertação ... pressupõe a busca, através do diálogo e do debate, de diretrizes e propostas consensuais ou majoritárias em questões estruturais para o desenvolvimento econômico e social do Brasil. Um esforço que objetiva a celebração de um "novo Contrato Social" - uma nova vontade política majoritária para recoesionar a sociedade brasileira na construção de uma nação moderna, democrática e socialmente solidária" (CDES, 2005). 
Contudo, convém observarmos que a agenda de negociação desse Conselho, durante a sua fase inicial, ficou circunscrita às reformas previdenciária e tributária.

\section{Síntese das Formas de Mediação Política no Brasil}

Neste tópico, aglutinaremos os principais momentos da história brasileira, referentes à economia política da estrutura de representação de interesses da classe empresarial nacional. A análise conjunta do processo histórico da evolução do Estado e desse relevante grupo de interesse, empreendida nos tópicos anteriores, permitiu a visualização das diversas configurações de mediações dos interesses empresariais nas arenas constituídas pelo Estado. Ressaltamos que foram extraídos, apenas, os momentos históricos que apresentaram alguma alteração nas formas de representação de interesse empresarial na estrutura estatal. Assim sendo, passamos, agora, a sumariar as modalidades de acesso desse segmento societal nas diversas configurações desenvolvidas pelo Estado brasileiro.

A compreensão dos modelos de representação política requer a identificação, descrição e análise de três elementos, quais sejam, os atores societais relevantes, as estruturas ${ }^{34}$ de relações interorganizacionais, e os padrões de interação com os agentes estatais tomadores de decisões. A representação dos interesses empresariais em vigor apresenta uma estrutura dual e multipolar cuja origem remonta à década de 1930. Ela se caracteriza pela "... convivência entre um formato corporativo instaurado e supervisionado pelo Estado e uma rede de associações paralelas, funcionando à margem do sistema oficial” (BOSCHI et al. (2000: 21). A vertente corporativa é regulamentada pelo Estado, detém monopólio de representação, e é estruturada tanto em termos hierárquicos como funcionais. As entidades corporativas oficiais são constituídas, segundo o ramo de atividade econômica, pelos sindicatos locais, federações regionais por estado federativo, e uma organização de âmbito nacional, expressa pelas confederações, que procuram expressar seus pontos de vista sobre assuntos de caráter mais geral.

A outra estrutura é de natureza voluntária, sem obrigatoriedade de afiliação, enfim, autônoma da intervenção regulatória estatal. Compreende as associações paralelas ou extracorporativas, independentemente organizadas em nível nacional, e que congregam empresas de um determinado segmento ou de setores congêneres. Basicamente, as associações dedicam-se à promoção e defesa de interesses localizados, compartilhados por segmentos do empresariado. Enquanto a criação dos sindicatos proliferou no período pré-1964, a profusão do associativismo foi verificada após aquele ano ${ }^{35}$. Cabe salientar, também, que essas modalidades organizacionais não são excludentes, ou seja, a criação de uma associação pode ocasionar a formalização de um sindicato, e vice-versa, caracterizando, dessa forma, um modelo de representação sobreposto e de dupla afiliação.

Descritas as frações institucionais do ator empresarial e a estrutura de representação dessa classe societal, discorreremos sobre o seu padrão de ação coletiva e as redes de conexão com as esferas do Estado. As duas modalidades de mediação apresentam um modelo simétrico no sentido de que é comum uma firma apresentar dupla filiação, ou seja, pertencer tanto ao sindicato regulamentado pelo Estado como à associação representativa do seu setor econômico. Procedimento semelhante é adotado pelas lideranças empresarias das duas formas de acesso às instâncias estatais. Ambas as estruturas de organização de interesse interagem e

34 À guisa de ilustração, Cardoso (1964, p. 70) exemplificou alguns tipos de estrutura social, lato sensu: divisão do trabalho, especialização das profissões, utilização de tecnologias, camadas sociais, distribuição de poder, instituições e representações sociais.

${ }^{35}$ A tendência histórica de formação de sindicatos remonta aos estágios iniciais do processo de industrialização, ao passo que a criação de associações está concentrada no período mais recente de industrialização, ou seja, a partir de 1964 (BOSCHI et al., 2000 , p. 31). Esses autores complementaram “... que o processo de criação de organizações de interesse do setor industrial está, grosso modo, vinculado às fases da industrialização e à natureza do regime político". 
compartilham a mesma elite dirigente. Contudo, em função do tema de negociação, a estrutura oficial e a de associação paralela podem apresentar interesses convergentes e complementares, ou, de modo diverso, desenvolver uma dinâmica competitiva.

Ademais, como salientou Diniz (2007), a formação da identidade coletiva e a incorporação política do empresariado ocorreu, apenas, pela via do Estado, sem a participação dos partidos políticos. A fortiori, prevaleceram as práticas voluntaristas e personalistas que, ato contínuo, contribuíram para a formação de uma cultura e práxis política independente dos partidos e do Congresso, instituições tradicionais promotoras de interesses coletivos. O padrão institucional assimétrico entre o Executivo e o Legislativo, que caracteriza as relações dessas duas funções do governo nacional está presente, também, nas formas de mediação exercidas pelo empresariado.

A existência de dissensões entre essas formas de associação de interesses releva uma fragilidade estrutural desse modelo de representação empresarial. Essa trama institucional caracterizada pela existência de múltiplos sindicatos locais, aglutinados em diversas federações estaduais, que se consolidam em uma confederação nacional que coexistem com entidades associativas nacionais não-estatais, é replicada para os diversos setores econômicos. Destarte, inexiste uma entidade aglutinadora em nível nacional dos interesses empresariais, o que inviabiliza a pactuação de interesses suprassetoriais, e a maior envergadura de políticas destinadas a essa classe societal. Predomina, portanto, a atuação política das organizações especializadas e estruturadas no corporativismo setorial36. Apesar da multiplicidade de interesses na estrutura de articulação política dos empresários, foi possível a obtenção de consenso em torno das diretrizes norteadoras do projeto de industrialização por substituição de importações da década de 1950, e nos projetos desenvolvimentistas empreendidos pelo Estado burocrático-autoritário.

A partir do final da década de 1980, foram criadas outras formas de organização empresarial, distintas das corporações e associações de classe, não orientadas diretamente para a representação de seus interesses junto às esferas estatais. A estrutura de representação então existente, alicerçada nas entidades corporativas e complementadas pelas entidades civis constituídas em formas de associações, estava adstringida à consecução de interesses mais imediatos dos segmentos setoriais que representavam. Ademais, naquela época, afigurava-se um contexto conturbado pela conjugação das crises política e econômica (BIANCHI, 2001).

Com o objetivo de discutir a redefinição do papel do empresariado como ator político e criar uma arena transsetorial de discussão de um projeto nacional de desenvolvimento econômico e social, que suplantasse os interesses imediatistas, particularistas, segmentários e setoriais característicos dessa classe social, e que arrefecesse os efeitos centrífugos dos interesses divergentes, foram constituídas organizações civis de estudos e pesquisas para preencher o vácuo decorrente da ausência de entidades suprassetoriais. Não foram criadas, essencialmente, para a representação de interesses empresariais. Estimularam, inclusive, o diálogo com as classes trabalhadoras e a superação dos conflitos entre capital e trabalho, encetando, pelo lado empresarial, uma nova configuração de interação entre os principais agentes econômicos, de corte neocorporativista, onde se congregam em um fórum tripartite, o Estado, os empresários e trabalhadores para a resolução dos conflitos distributivos dos recursos públicos. Dentre essas entidades, destacaram-se o Pensamento Nacional das Bases Empresariais - $\mathrm{PNBE}^{37}$, o Instituto de Estudos para o Desenvolvimento

\footnotetext{
36 "O desenho institucional prevalecente e o padrão de ação coletiva historicamente consolidado circunscreveram o caso brasileiro às modalidades de corporativismo de níveis micro e intermediário (mesocorporativismo e corporativismo setorial), dados o caráter limitado dos interesses envolvidos e o alcance restrito das negociações possíveis" (DINIZ, 2000: 85).

37

O PNBE, constituído em 1987 a partir de uma dissidência da FIESP, configurou-se como 'um movimento de base' e não de cúpula, orientado para a discussão de grandes questões nacionais e intervenção em momentos relevantes da conjuntura nacional (DINIZ e BOSCHI, 1993).
} 
Industrial - IEDI $^{38}$, e os institutos liberais ${ }^{39}$. Em síntese, o PNBE expressa um conjunto empresarial que busca uma representatividade maior àquela permitida pela estrutura patronal dual então existente, e que se caracteriza pela ação prática nos campos político, econômico e social, procurando interagir eficazmente nos principais momentos da conjuntura nacional. Por sua vez, o IEDI apresenta um corte mais programático, enquanto os institutos liberais apresentam um perfil eminentemente ideológico (DINIZ, 1993; 2000; DINIZ e BOSCHI, 1993; BOSCHI et al., 2000). A criação desses institutos de pesquisa coincidiu com difusão dos preceitos neoliberais propalados pelos governos da Inglaterra e dos EUA, na década de 1980. Uma leitura alternativa de suas constituições pode ser empreendida a partir da suposição de que esses centros de estudos visavam difundir uma ideologia neoliberal. Destarte, correspondem aos 'intelectuais orgânicos' de Gramsci, ou às comunidades epistêmicas ${ }^{40}$. Essas entidades, que apresentaram relevância no final da década de $1980 \mathrm{e}$ início de 1990, tornaram-se gradativamente obscuras com a acentuação do modelo desenvolvimentista dinamizado pelo mercado (DINIZ e BOSCHI, 2004).

A compartimentalização do aparato do Estado retroalimenta a lógica da fragmentação da estrutura de representação dos interesses empresariais, cuja imanência heterogênea e multifacetada é observada no nível da firma, no tamanho do sindicato, na regionalização, e no setor da atividade econômica. Inobstante, tanto o sistema dual de representação como a inexistência de uma autoridade empresarial una dotaram essa configuração de uma flexibilidade representativa e capaz de se adaptar às diferentes conjunturas políticoeconômicas (DINIZ e BOSCHI, 1993; 2004; BOSCHI et al, 2000). A plasticidade entre os modelos oficial e associativo (estrutura de representação dual), a constituição pelo Estado de novas entidades em fóruns negociais (v.g., conselhos), as práticas de lobbying, a utilização de métodos clientelistas, e o exercício de vínculos pessoais possibilitaram, não apenas, a manutenção da estrutura corporativa concebida na década de 1930, mas, sobretudo, consolidaram esse sistema simultaneamente centralizado e diferenciado, endogenamente disjuntivo, de coexistência e representação política da classe empresarial.

Por um lado, esse arranjo de representação complexo e maleável inviabiliza a constituição de plataformas abrangentes que representem um interesse nacional, mesmo que sua coordenação seja adstrita à classe empresarial. Contudo, essa comunhão de formatos corporativos, associativos, e clientelistas, acionados alternativamente e, por vezes, simultaneamente predatórios e pluralistas refletem, de um modo, as mudanças das plataformas político-econômicas do Estado brasileiro - e.g. do modelo de industrialização substitutiva de importações para o desenvolvimento induzido pelo mercado, caracterizado pelo redimensionamento do tamanho do Estado e pela abertura comercial da economia - e, de outro modo, a crescente complexidade da estrutura social nacional.

Enfim, esse processo mutacional decorrente da crescente densidade organizacional das representações dos interesses empresariais ocasiona a disjuntiva entre a versatilidade da utilização dos recursos de poder, de um lado, e o aumento da fragmentação da estrutura de representação da classe empresarial, de outro (DINIZ e BOSCHI, 2004).

38 O IEDI foi criado em 1989 [, em São Paulo,] e reúne atualmente 45 empresários representantes de grandes empresas nacionais" (IEDI, 2005). Foi constituído com vistas à discussão e formulação de propostas globais de desenvolvimento econômico do país (GROS, 1993). Diniz e Boschi (2004, p. 55) ofereceram uma perspectiva alternativa. Explicaram que o IEDI foi criado "... por iniciativa de um pequeno número de grandes empresários ligados a setores da grande indústria nacional ... setores que seriam mais afetados pelas politicas de abertura da economia e privatização das estatais, seus clientes preferenciais".

39 Os institutos liberais são instituições sem fins lucrativos “... voltada[s] para a pesquisa, produção e divulgação de idéias, teorias e conceitos que revelam as vantagens de uma sociedade organizada com base em uma ordem liberal”. (INSTITUTO LIBERAL, 2005).

${ }^{40}$ (hediterranean, publicado em 1990, Peter Haas conceltuou comunidade epistêmica como sendo um grupo acadêmico e/ou de profissionais que compartilham valores e arcabouços teóricos, de modo que apresentam uma compreensão comum para um determinado problema e sua solução. 


\section{Referências}

BIANCHI, Alvaro. Crise e Representação Empresarial: o Surgimento do Pensamento Nacional das Bases Empresariais. Revista Sociologia e Política, $n^{\circ}$ 16, p. 123-142, junho, 2001.

BOSCHI, Renato; DINIZ, Eli; SANTOS, Fabiano. Elites Políticas e Econômicas no Brasil Contemporâneo: a Desconstrução da Ordem Corporativa e o Papel do Legislativo no Cenário Pós-Reformas. São Paulo: Fundação Konrad Adenauer, Série Pesquisas, no. 18, 2000.

CAMARGO, Aspásia. A Federação Acorrentada: Nacionalismo Desenvolvimentista e Instabilidade Democrática. In: XVI Encontro Anual da ANPOCS, 20-23 de outubro, Caxambu/MG, 1992.

CARDOSO, Fernando Henrique. Empresário Industrial e Desenvolvimento Econômico no Brasil. São Paulo: Difusão Européia do Livro, 1964. . Autoritarismo e Democratização. São Paulo: Paz e Terra, 1977.

CDES - Conselho de Desenvolvimento Econômico e Social da Presidência da República. Disponível em: < http://www.presidencia.gov.br/estrutura_presidencia/conselhos / > . Acesso em 01.12.2010.

COUTINHO, Luciano e FERRAZ, João Carlos (coords.). Estudo da Competitividade da Indústria Brasileira. Campinas: Papirus, $4^{\mathrm{a}}$ ed., 2002.

CRUZ, Sebastião Carlos Velasco e. Empresários e o Regime no Brasil: A Campanha contra a Estatização. Tese de Doutorado. São Paulo: USP, 1984.

DINIZ, Eli. Empresário, Estado e Capitalismo no Brasil: 1930-1945. Rio de Janeiro: Paz e Terra, Coleção Estudos Brasileiros, $\mathrm{n}^{\circ} 27,1978$.

(org.). Neoliberalismo e Corporativismo: as Duas Faces do Capitalismo Industrial no Brasil. In: Empresários e Modernização Econômica: Brasil Anos 90. Florianópolis: Editora da UFSC, IDACON, 1993.

Globalização, Reformas Econômicas e Elites Empresariais: Brasil anos 1990. Rio de Janeiro: FGV,

2000 .

FGV, 2007

(org.). Globalização, Estado e Desenvolvimento: Dilemas do Brasil no Nove Milênio. Rio de Janeiro:

DINIZ, Eli; BOSCHI, Renato. Empresariado Nacional e Estado no Brasil. Rio de Janeiro: Forense-Universitária, Coleção Brasil - Análise \& Crítica, 1978.

\footnotetext{
1993. Brasil: um Novo Empresariado? Balanço de Tendências Recentes, p. 115-131. In DINIZ, Horizonte: Editora UFMG, 2004.

Empresários, Interesses e Mercado: Dilemas do Desenvolvimento no Brasil. Belo
}

DRAIBE, Sonia. Rumos e Metamorfose: Estado e Industrialização no Brasil, 1930/1960. Rio de Janeiro: Paz e Terra, 1985.

FAORO, Raymundo. Os Donos do Poder: Formação do Patronato Político Brasileiro, $3^{\text {a }}$ ed., revisada. São Paulo: Globo, 2001.

FERNANDES, Florestan. A Revolução Burguesa no Brasil. Rio de Janeiro: Zahar, 1976. 
IEDI - Instituto de Estudos para o Desenvolvimento Industrial. Disponível em <http://www.iedi.org.br/cgi/cgilua.exe/sys/start.htm?UserActiveTemplate=iedi\&sid=23>. Acesso em 19.04.2005.

INSTITUTO LIBERAL, Disponível em: <http://www.institutoliberal.org.br/> . Acesso em 01.12.2010.

MAINWARING, Scott. Sistemas Partidários e Novas Democracias: o Caso do Brasil. Rio de Janeiro: Ed. FGV, 2001.

MANCUSO, Wagner Pralon; OLIVEIRA, Amâncio Jorge de. Abertura Econômica, Liderança Política e Ação Coletiva do Empresariado no Brasil Contemporâneo: os Planos Doméstico e Internacional. Versão preliminar. Disponível em: < http://neic.iesp.uerj.br/textos/Amacio\&Wagner.pdf >. Acesso em 01.12.2010.

MELlo, João Manuel Cardoso de. O Capitalismo Tardio: Contribuição à Revisão Crítica da Formação e do Desenvolvimento da Economia Brasileira. São Paulo: Brasiliense, 1982.

THEODORO, Mário. Participação Social em Políticas Públicas: os Conselhos Federais de Política Social - o Caso CODEFAT. Texto para Discussão, IPEA, nº 931, dez., 2002.

VELASCO Jr., Licínio. A Economia Política das Políticas Públicas: Fatores que Favoreceram as Privatizações no Período 1985/94. Textos para Discussão, BNDES, v. 54, abril, 1997. 